\title{
SUPPORTING CROSS-CULTURAL UNIVERSITY EDUCATION
}

\author{
Emiel van Puffelen (D), Marijke van Oppen \\ 4TU.Centre for Engineering Education (4TU.CEE) \\ Wageningen University \& Research \\ Wageningen, The Netherlands
}

\begin{abstract}
Current and future students will work in a rapidly changing world that differs significantly from the present situation. We do not know exactly which new learning outcomes will be needed, but population growth combined with globalisation and digitalisation makes it clear that a global mind-set and the ability to effectively operate in a multicultural environment will be crucial. Student immersion into different cultures within a university might facilitate the development of intercultural competence within "the international classroom"; however, the competencies and support of teaching staff are also essential for optimising this process. This paper shows the approach of Wageningen University towards the international classroom, including its student population, policies, informational resources and support activities. The teachers are relatively experienced with the international classroom, but additional training was requested and developed. The first six training sessions provided, received positive evaluations, showing that even in a situation with experienced teachers and clear policies and support for the international classroom, additional training is still valuable. The overview of policy, activities, support and training might help other universities to reflect on their approach towards cross-cultural university education.
\end{abstract}

\section{KEYWORDS}

Diversity, 21st century skills, Cross-cultural, Teacher training, Standards: 2,3,7,8,9,10

\section{INTRODUCTION}

The global population has increased from under one billion 200 years ago to over 7.7 billon today (Roser \& Ortiz-Ospina, 2019; World Population Review, 2020). The growth rate has declined to $1.12 \%$ in 2018 , but the population is still expected to climb to more than 9 billion by 2040 (World Population Review, 2020). Combined with increasing urbanisation, the effects of this enormous growth in a short time span are quickly reshaping our world.

In addition, the human population is innovating society ever more quickly, which, according to Kamp (2016), is the result of three major forces:

1. globalisation and digitalisation,

2. the horizontalization of the socio-economic world,

3. the blending of technical, economic and societal cultures. 
These forces, combined with population growth and urbanisation, have a strong impact on technology, business, and organisational and social systems. Current and future students will therefore work in a rapidly changing world that differs significantly from the present situation. We do not know exactly which new learning outcomes will be needed, but population growth combined with the first force (globalisation and digitalisation) makes it clear that a global mind-set and the ability to effectively operate in a multicultural environment will be even more crucial in the future.

In addition, global challenges such as clean energy and climate action, as formulated by the United Nations (2015), will require effective intercultural cooperation (Hofstede, Hofstede \& Minkov, 2010). Tomorrow's workforce will need to undergo a shift in cultural perspective and a bridging of behaviour across cultural differences. This requires students to learn to shift from a mono-cultural mind-set of denial and polarisation to the intercultural mind-set of acceptance and adaptation, as described by Hammer (2012).

Wageningen University \& Research (Wageningen University) expects its graduates to be able to work on global challenges, compete for jobs in an international environment and function well in a multicultural setting. It considers an international classroom, in which the experiences of students from different countries can be shared, to be one of the best settings for learning intercultural skills (Wageningen University, 2017). Immersion into different cultures might not be sufficient to facilitate the development of intercultural competence however, as shown by Hammer (2012) for a large English-speaking country (although this might be more effective for universities in small non-English-speaking countries). An efficient utilisation of international groups for intercultural learning ("the international classroom") requires the competencies and support of teaching staff to facilitate this process.

Wageningen University has a long tradition of supporting the international classroom through its policies, informational resources and activities. An inquiry among Programme Directors led to requests for additional international classroom training for teaching staff. This paper provides an overview of the existing policies and support for the international classroom and presents the results of the training programme developed in response to the requests of the Programme Directors.

The entire overview of policy, activities, support and training might help other universities to reflect on their approach towards cross-cultural university education. 


\section{THE APPROACH OF WAGENINGEN UNIVERSITY}

\subsection{Intercultural classroom composition: PhD students}

Wageningen University has $2121 \mathrm{PhD}$ students from 109 countries (Wageningen University, 2020). Only $33 \%$ of them are Dutch, while 37 nationalities are each represented by 10 or more PhD students. The top 12 most frequent countries of origin are distributed across four continents, as shown in Table 1.

Table 1. Top 12 most frequent countries of origin for $\mathrm{PhD}$ candidates at Wageningen University, and the number of PhD candidates from each of them (January 2020)

\begin{tabular}{|ll|ll|ll|}
\hline The Netherlands & 711 & Italy & 53 & Kenya & 39 \\
China & 305 & Ethiopia & 48 & Spain & 36 \\
Germany & 82 & Mexico & 45 & Greece & 34 \\
Indonesia & 74 & India & 45 & Brazil & 28 \\
\hline
\end{tabular}

\subsection{Intercultural classroom composition: MSc students}

Since 2002, all Master's programmes at Wageningen University are taught in English, resulting in a large enrolment of students from outside the Netherlands. In $2019,62 \%$ of the first-year MSc students were Dutch, while the rest came from all over the world. (Table 2).

Table 2. First-year MSc enrolment by nationality (October 2019)

\begin{tabular}{|lr|lr|}
\hline \multicolumn{2}{|l|}{ All first-year MSc students } & 2,498 \\
\hline & & Chinese & 202 \\
Dutch & 1,559 & Indonesian & 46 \\
& & Indian & 43 \\
Italian & 98 & American & 18 \\
German & 88 & Mexican & 14 \\
Greek & 63 & Ghanaian & 14 \\
Spanish & 54 & Colombian & 13 \\
French & 32 & Turkish & 12 \\
Belgian & 16 & South Korean & 8 \\
Portugese & 15 & Kenyan & 7 \\
Britisch & 11 & Thai & 6 \\
& & Taiwanese & 4 \\
& & Tanzanian & 4 \\
\hline Total other European & 444 & Total non-European & 495 \\
\hline
\end{tabular}




\subsection{Intercultural classroom composition: BSc students}

Until 2018, the first-year BSc courses were taught partially in Dutch, resulting in a low BSc participation rate for non-Dutch students (most of whom came from Belgium and Germany). From September 2018 onwards, six of the 19 BSc programmes are offered entirely in English, which has resulted in $7.7 \%$ of first-year BSc students coming from outside the Netherlands in September 2019. This percentage is expected to increase over the next ten years.

\subsection{International classroom policy}

The strategic plan of Wageningen University states that "We prepare all our students for work and life in an international, intercultural and multi-stakeholder environment".

The policy regarding intercultural competence and the international classroom is described in more detail in the Wageningen University Vision for Education (Wageningen University, 2017):

"We expect all our students to be open minded, eager to develop multicultural skills and to have a good level of proficiency in English. In the international classroom, lecturers are encouraged to use the experience and background of the (international) students in their courses. We strive for a balance in the international classroom, monitoring the composition of classes in terms of incoming students and adapting our recruitment strategies when necessary. Almost all our students go abroad or work in an international company or organisation during their time at Wageningen University. We maintain an extensive network of international partners to facilitate student exchange, and offer the possibility of double and joint degrees. On campus, we provide a welcoming atmosphere for people from all over the world by using English in all our communications, organising international events and by providing essential administrative and practical support."

\subsection{Tackling more differences in engagement caused by increased diversity.}

Biggs and Tang (2011) analysed changes in the nature of higher education and reported that they result in higher levels of diversity among students. The consequences of this are that universities must deal with larger differences in engagement between students. Wageningen University is experiencing this phenomenon, and tackles it by implementing flexible learning paths and smart combinations of teacher and learning activities (van Puffelen, 2017), particularly with the use of balanced combinations of online and face-to-face teaching and learning activities (van Puffelen, van Berkum \& Diederen, 2018). 


\subsection{Information and support activities}

Wageningen University is constantly improving its information and support activities for the international classroom. In 2019, the centrally organised activities and informational resources consisted of:

- Guidelines on working in multicultural settings

- One World Week: a week of many activities celebrating diversity

- An extensive website for international students and staff, covering many topics such as healthcare, housing and international communities on Facebook.

There are also information and support activities specifically produced for international staff, including:

- A buddy system for new international staff

- A monthly partner programme with social activities for staff and their families

- Workshops providing an introduction to the Netherlands (6x per year) Partners can also attend

- A language policy: all staff must have a certain level of English language

- International staff groups organising social events with an international scope

- Intercultural Competences training within the didactic programme for teachers

- Centre for Immigration procedures and support for incoming international staff

- Career support for partners

- Information for international staff regarding tax and salary/scholarship regulations

- Employee survey questions on satisfaction about international orientation

- A travel policy and Erasmus mobility for staff members to learn at another university

\section{ADDITIONAL SUPPORT}

\subsection{Questionnaire}

Policy implementation and the provision of information and support are ongoing activities that can be extended with additional actions if required. In December 2017, a small-scale questionnaire with options for additional support was offered to the Directors of the study programmes. The Directors of 11 study programmes responded, for a total of eight people (some are directors of multiple programmes). The results are shown in Table 3. 
Table 3. Total number of requests for each support option

\begin{tabular}{|lc|}
\hline Support requested & $\begin{array}{c}\text { Total } \\
\text { number }\end{array}$ \\
\hline $\begin{array}{l}\text { A toolbox with materials, good practices } \\
\text { and literature on Internationalisation }\end{array}$ & 8 \\
\hline Training of staff & 8 \\
\hline Pre-, during and post-course training for students & 1 \\
\hline Intensive tutor training & 2 \\
\hline Materials for student workshops on intercultural communication & 8 \\
\hline $\begin{array}{l}\text { Exchange with others (such as Programme Directors) } \\
\text { working on Internationalisation }\end{array}$ & 7 \\
\hline Support from an expert in this field on ... & 2 \\
\hline $\begin{array}{l}\text { Training for teachers on how to teach students from } \\
\text { other cultures and backgrounds }\end{array}$ & 2 \\
\hline $\begin{array}{l}\text { Training for international teachers on how to work and learn with } \\
\text { colleagues or students from other cultures and backgrounds }\end{array}$ & 4 \\
\hline
\end{tabular}

Of course, this was a very limited survey. Nevertheless, there seemed to be a clear request from the Programme Directors for additional support. The toolbox and materials requested were developed by the EQUiiP programme (EQUiiP, 2020). This is supplemented by a toolbox developed within 4TU.CEE (4TU.CEE, 2020b). The additional training programs requested were developed by Wageningen University. They are described below.

\subsection{The additional training programme}

The development of the training programme started at the beginning of 2018 and the first six training sessions were offered between May 2018 and March 2019, as shown in Table 4. The training programme continues the next three years, with upcoming training sessions displayed on the 4TU.CEE event webpage (4TU.CEE, 2020a). The sessions are available for staff at all four universities within 4TU.CEE, occasionally also for other universities and organisations, and offered on any requested location.

Table 4. The first six training sessions offered

\begin{tabular}{|lr|}
\hline Training session & \multicolumn{1}{c|}{ Date } \\
Supporting international students: & \\
how to turn fear of failure into competency & $9-5-2018$ \\
How to beat procrastination & $15-6-2018$ \\
Inclusiveness for better study results & $18-9-2018$ \\
From emotional to cultural intelligence & $21-9-2018$ \\
Culturally appropriate and effective feedback & $14-12-2018$ \\
Teaching in the international classroom & $21-3-2019$ \\
\hline
\end{tabular}


All training sessions were evaluated using the online university course evaluation system to ensure an objective and anonymous evaluation. There were 13 questions about the usefulness and quality of the course and its constituent parts. They were scored using a fivepoint Likert scale, ranging from 1 (strongly disagree) to 5 (strongly agree), with 3 representing a neutral score. There were two additional questions on the course as a whole, which were marked on a score of 1 (very bad) to 10 (excellent). The response rates for the sessions ranged from $33 \%$ to $74 \%$, which is normal for an anonymous online evaluation. The results are shown in Table 5.

Table 5. Evaluation results of the training sessions (average of all participants)

\begin{tabular}{|c|c|c|c|c|c|c|}
\hline & 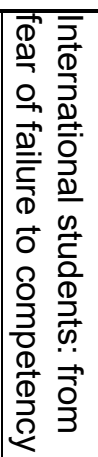 & 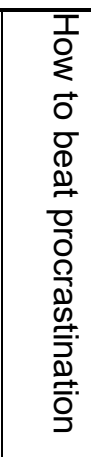 & 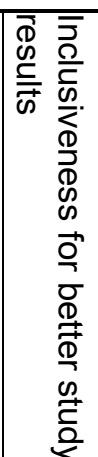 & 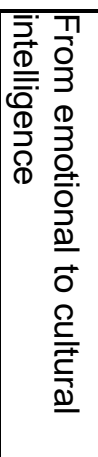 & 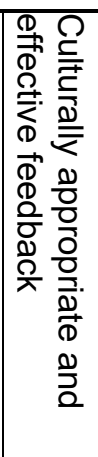 & 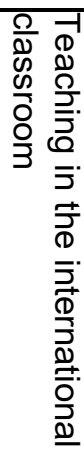 \\
\hline The learning outcomes were clear to me & 4.4 & 3.9 & 3.6 & 4.3 & 4.2 & 4.5 \\
\hline The course activities fit well with the learning outcomes & 3.8 & 3.9 & 3.6 & 4.5 & 3.4 & 4.3 \\
\hline $\begin{array}{l}\text { The achievement of the learning outcomes contributed } \\
\text { to a better performance in my teaching/guiding }\end{array}$ & 4.3 & 4.1 & 3.5 & 4.0 & 4.4 & 4.3 \\
\hline The course subjects were relevant to the learning outcomes & 4.2 & 4.1 & 3.8 & 4.0 & 3.6 & 4.2 \\
\hline The order of subjects discussed in the course was good & 4.4 & 4.3 & 3.8 & 4.3 & 3.4 & 4.4 \\
\hline The format of the course stimulated to participate actively & 4.6 & 4.4 & 4.3 & 4.8 & 4.6 & 4.6 \\
\hline $\begin{array}{l}\text { The course format stimulated me to reflect critically } \\
\text { on my experiences and learning process }\end{array}$ & 4.3 & 4.3 & 4.1 & 4.0 & 4.0 & 4.6 \\
\hline $\begin{array}{l}\text { The reference material is useful and relevant to the } \\
\text { learning outcomes }\end{array}$ & 4.1 & 3.8 & 3.4 & 4.0 & 4.2 & 4.2 \\
\hline $\begin{array}{l}\text { The training methods helped me to achieve } \\
\text { the course learning outcomes }\end{array}$ & 3.9 & 3.7 & 3.6 & 4.5 & 3.3 & 4.0 \\
\hline $\begin{array}{l}\text { There were sufficient opportunities to exchange } \\
\text { ideas with, and learn from, fellow course members }\end{array}$ & 4.4 & 4.2 & 3.8 & 4.5 & 5.0 & 4.3 \\
\hline $\begin{array}{l}\text { The feedback and interventions by the trainer(s) } \\
\text { helped me to achieve the course learning outcomes }\end{array}$ & 4.0 & 4.3 & 3.8 & 4.8 & 3.8 & 4.0 \\
\hline $\begin{array}{l}\text { The course content fits my knowledge, experience } \\
\text { and personal goals }\end{array}$ & 3.9 & 4.1 & 3.8 & 4.8 & 3.4 & 4.5 \\
\hline $\begin{array}{l}\text { What I learned in the course can be directly used } \\
\text { in my teaching practice }\end{array}$ & 4.1 & 4.0 & 3.4 & 4.3 & 3.6 & 4.0 \\
\hline $\begin{array}{l}\text { Mark between } 1 \text { (very bad) and } 10 \text { (excellent) for your own } \\
\text { contribution to the course }\end{array}$ & 7.2 & 7.6 & 7.3 & 8.3 & 7.4 & 7.2 \\
\hline Mark between 1 and 10 for the course as a whole & 8 & 8.1 & 7.3 & 8.5 & 6.6 & 2 \\
\hline
\end{tabular}


For all training sessions and questions with answers on the five-point Likert scale, the average score was above neutral, ranging from 3.3 to 5.0 (with an SD between 0.4 and 1.5). These relatively positive results were also seen on the ten-point scale evaluation of the course as a whole. Four of the average course scores were above 8 (very good), one was 7.3 (good), and one was acceptable but with room for improvement (6.6). The first five of the six training sessions were newly developed, and their relatively well-received first versions are a good start. Of course, the evaluation results also contained text remarks and suggestions, which will be used to further improve the next versions of the training sessions.

\section{DISCUSSION AND CONCLUSION}

The MSc and PhD students of Wageningen University come from all over the world. Their course groups are truly multicultural, albeit with relatively large numbers of students from the Netherlands and Asia. Most Wageningen University teachers have experience with this environment, and some international classroom training is included in the teacher training programme for the University Teachers Qualification (in use from 2009 onwards).

Wageningen University supports the effective use of the international classroom through its policies, informational resources and actions; however, additional requests for further support, including training, were made by Programme Directors.

The evaluation of the first six additional training sessions showed that such training is useful, even in an environment with intercultural experienced teachers. Of course, it will take a few years to train sufficiently large numbers of teachers to detect the effects of these courses on a university scale, but the positive evaluations of these training sessions suggest that they improve the ability of teachers to utilise the intercultural classroom for the development of intercultural competence. For many students, international classroom training is supplemented with intercultural learning during internships and research performed in other countries and cultures. These experiences might also benefit from teachers provided with additional support training, which will help teachers in their role as long-distance mentors.

\section{FUTURE WORK}

The training programme is continuously improved using (post) session communication with participants and the information of the online course evaluation system. This has also resulted in more focus on the dynamic of intercultural interdisciplinary groupwork from 2020 onwards. There is a high demand for the sessions at the four universities and the sessions are continuously scheduled a year ahead (4TU.CEE, 2020a). This is supplemented with dedicated sessions on request.

Wageningen University started six international BSc programmes in 2018, resulting in an increase in the enrolment of international undergraduate students. From 2020 onwards, a research programme explores the effects of that shift in more detail. 


\section{ACKNOWLEDGEMENTS}

We would like to thank our partners within 4TU.CEE, especially at the University of Twente, for their contribution to the discussions and text of the Programme Directors questionnaire. We would also like to thank colleagues in the Quality and Strategic Information Section of Wageningen University for their help with the provision of enrolment data and the evaluation of the training sessions.

\section{REFERENCES}

4TU.CEE. (2020a). Event webpage of the 4TU.Centre for Engineering Education. Retrieved from https://www.4tu.nl/cee/en/events/

4TU.CEE. (2020b). Internationalisation toolbox online. Retrieved from https://www.4tu.nl/cee/en/news/!/6514/internationalisation-toolbox-online/

Biggs, J. B., \& Tang, C. (2011). Teaching for Quality Learning at University (4th Revised edition ed.). Milton Keynes, United Kingdom: Open university press.

EQUiiP. (2020). Educational Quality at Universities for Inclusive International Programmes. Retrieved from https://equiip.eul

Hammer, M. (2012). The Intercultural Development Inventory: A new frontier in assessment and development of intercultural competence. In R. M. P. M. Vande Berg, \& K.H. Lou (Ed.), Student Learning Abroad (pp. 115-136). Sterling, VA: Stylus Publishing.

Hofstede, G. H., Hofstede, G. J., \& Minkov, M. (2010). Cultures and organizations : software of the mind. Maidenhead: McGraw-Hill.

Kamp, A. (2016). Engineering Education in a Rapidly Changing World; Rethinking the Vision for Higher Engineering Education (Second Revised Edition ed.). Delft: Delft University of Technology, Faculty of Aerospace Engineering.

Roser, M., \& Ortiz-Ospina, E. (2019). World Population Growth. Retrieved from https://ourworldindata.org/world-population-growth

United Nations. (2015). Transforming our world: The 2030 agenda for sustainable development. In Resolution adopted by the General Assembly 25 September 2015. New York, USA: United Nations.

van Puffelen, E. A. M. (2017). Designing blended engineering courses. Proceedings of the 45th SEFI Annual Conference 2017, Angra do Heroísmo - Terceira, Azores, Portugal. 1308-1312.

http://edepot.wur.nl/424719

van Puffelen, E. A. M., van Berkum, M., \& Diederen, J. (2018). Balancing online and face-to-face teaching and learning activities. Proceedings of the 14th International CDIO Conference, Kanazawa, Japan. 339-348. http://edepot.wur.nl/458051

Wageningen University. (2017). Vision for Education. Retrieved from Wageningen: https://www.wur.nl/en/show/Wageningen-University-Vision-for-Education.htm

Wageningen University. (2020). PROMIS: PhD information system of Wageningen University. World Population Review. (2020). Retrieved from http://worldpopulationreview.com/ 


\section{BIOGRAPHICAL INFORMATION}

Emiel van Puffelen is the leader of the 4TU.Centre for Engineering Education (4TU.CEE) at Wageningen University \& Research. At Wageningen University, he supervised the creation and full-scale operation of the University Teaching Qualification programme. He also developed MOOC production teams, knowledge clip studios, the education innovation consultancy, the educational portal, and a team for the innovation of the IT learning environment. He is a senior consultant for the innovation of higher education and has worked for national organisations. He has a special interest in activating learning, blended learning, training teaching staff, and the novel design of curricula and courses.

Marijke van Oppen has been coordinator of the 4TU.CEE at Wageningen University \& Research. She is one of the most active trainers of 4TU.CEE and has many years of experience in training and advising (University) Teachers, study advisors and counsellors. She is expert in the field of cross-cultural development and inclusion. She trains on topics like teaching in the international classroom and facilitating intercultural interdisciplinary groups. She is certified administrator of the Intercultural Development Inventory (IDI) the Global Competency Inventory (GCl) and the Intercultural Effectiveness Scale (IES).

\section{Corresponding author}

Ir. Emiel A.M. van Puffelen

4TU.Centre For Engineering Education

Wageningen University \& Research

P.O. Box 9101,

6700 HB Wageningen The Netherlands

31-317-484568

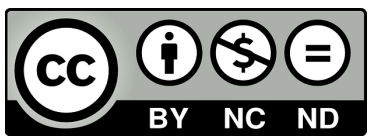

This work is licensed under a Creative Commons Attribution-NonCommercialNoDerivs 4.0 International License.

emiel.vanpuffelen@wur.nl 